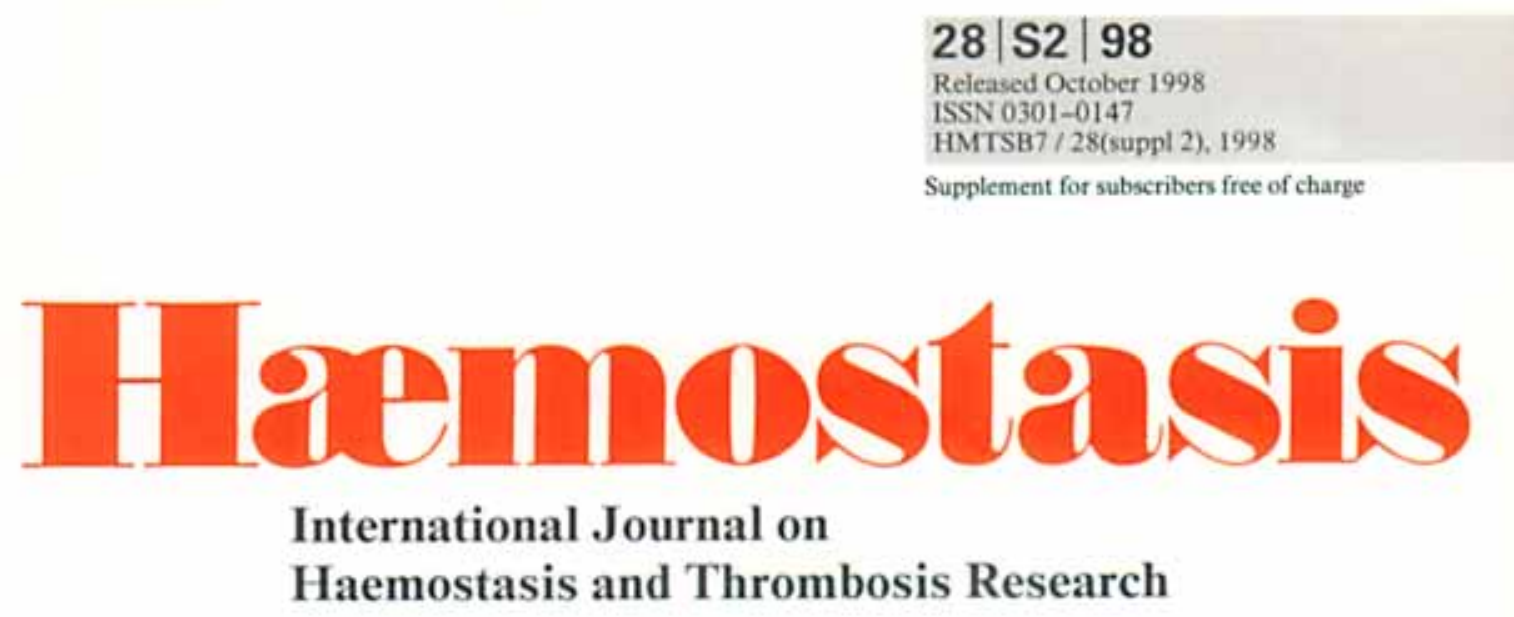

\title{
15th International Congress on Thrombosis
}

Antalya, Turkey, October 16-21, 1998

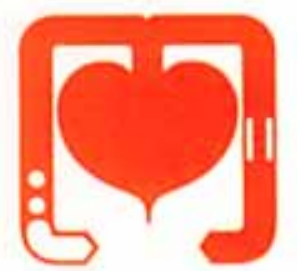

\section{A bstracts}

\section{Guest Editors}

S. Balkuv-Ulutin, Istanbul

T. Yardımcı, Istanbul

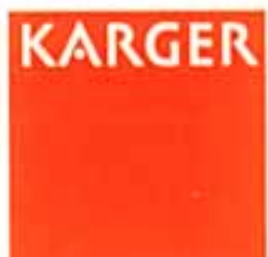


This issue contains the abstracts of the 15th International Congress on Thrombosis

Antalya, Turkey, October 16-21, 1998

and is not available online for technical reasons. 